\title{
ANTHROPOGENIC EVOLUTION \\ OF MORPHOLOGICAL FEATURES OF CHERNOZEMS
}

\author{
Mykola Kovalov ${ }^{1}$ \\ Vita Reznichenko
}

DOI: https://doi.org/10.30525/978-9934-588-15-0-132

Abstract. The objective of the article is to study the morphological properties of typical and ordinary heavy-clay and light-clay chernozems with grain-size distribution of the Buh-Dnipro region of the right-bank southern forest-steppe and northern Steppe. The article discloses the consistencies of development of soil-forming processes in the conditions of fairly long agricultural use. The analysis and assessment of transformational changes that have occurred in soils under the influence of agricultural use has been carried out. On the basis of generalization of materials of large-scale soil studies, modular semi-stationary lots were selected in order to identify the direction of changes of anthropogenically-modified typical and ordinary chernozems with heavy-clay and lightly-clay grain-size distribution using comparative-geographical, comparative-profile-genetic, comparative-analytic and other methods. These methods are based on the principle of modular lots. Topographic and soil maps (scale 1:25000 and 1:10000), materials and agrochemical studies of the state organization Kropyvnytskyi Branch of the Institute of Soil Conservation of Ukraine, as well as the materials on geology, geomorphology and hydrogeological structure were used. In the territory of the Buh-Dnipro region of the right-bank southern forest-steppe and northern Steppe, modular lots were selected and morphological studies were conducted within their boundaries. Soil sections were based on the principle of single difference: all factors of soil formation are almost the same, except anthropogenic, which in turn makes it possible to identify quantitative and qualitative changes in agro-ecological properties of the investigated soils as a result of agricul-

\footnotetext{
${ }^{1} \mathrm{PhD}$ of Agriculture, Senior Lecturer at the Department of Geoponics, Central Ukrainian National Technical University, Ukraine

${ }^{2} \mathrm{PhD}$ of Agriculture, Associate Professor at the Department of Geoponics, Central Ukrainian National Technical University, Ukraine
} 
tural use. Within the modular lots, representative soil sections were formed on lands of various economic uses, namely, forest, forest belts, grass lands, arable lands with and without mechanized cultivation. Within the modular lots, soil sections were made on one-level altitude-division surfaces, on similar elements of micro ground features, on similar soil-forming rocks, within one soil difference in the post-vegetation period. In the conditions of the Buh-Dnipro region of the right-bank southern forest-steppe and the northern Steppe of Ukraine, a comprehensive study of the composition and properties of typical and ordinary chernozems was conducted. Changes of morphological properties of typical and ordinary chernozems with heavyclay and lightly-clay grain-size distribution depending on their agricultural use have been identified. On the example of numerous variants and a comprehensive programme of observations, the conservativeness of soils with heavy-clay and lightly-clay grain-size distribution was not confirmed, but significant changes of their morphological properties were revealed. The complex of indicators revealed the degradation of the properties of typical and ordinary chernozems under anthropogenic pressure, especially in surface horizons. The tendency of anthropogenic transformation of soils, which is to increase the differentiation of the profile by morphological features due to agricultural use, has been established. The nature of intensification and direction of degradation processes of soils of agro-ecosystems has been revealed.

\section{Introduction}

Significant exacerbation of the ecological situation and the formation of pre-crisis, crisis, and often catastrophic conditions of land resources within the Buh-Dnipro inter-stream area require a detailed study of the processes related to agricultural activity. Only in this way the methodological basis for the improvement of the soil status of agro-ecosystems can be developed and the losses of agricultural production from the irrational use of outdated engineering technologies can be estimated.

The problem of economically advantageous and environmentally sound land use of hundreds of thousands of hectares of chernozem cannot be solved without a detailed study of anthropogenically transformed lands.

The objective of the research is to study the morphological properties of typical and ordinary chernozems with heavy-clay and lightly-clay grain- 
size distribution of the Buh-Dnipro region of the right-bank of southern forest-steppe and northern Steppe. It is also important to study the consistencies of development of soil-forming processes under the conditions of fairly long agricultural use.

In accordance with the objective of the research, it was envisaged to solve the following tasks:

- to analyze and assess the factors of soil formation of the studied territory of Ukraine;

- to substantiate the choice of semi-stationary lots for the study of the evolution of anthropogenically-transformed typical and ordinary chernozems;

- to analyse the changes in the morphological properties of typical and ordinary chernozems with heavy-clay and light-clay grain-size distribution depending on their use;

- to identify the nature of changes in soil properties;

- to determine the direction of anthropogenic soil evolution.

\section{Morphological and genetic characteristics of the objects under study}

Modular lot 1 (Oleksandrivka)

Semi-stationary soil lot № 1 in the territory of Chervono-Nerubaivka ecosite of Oleksandrivka forestry of Oleksandrivka district (Figure 3.1). The experimental lot is located in the territory of Chervono-Nerubivka forestry in the north-eastern outskirts of the village Pidlisne. The area is flat with oak and maple forest, plantation age is 50 years. The grass cover is typical forest vegetation (blackberry,

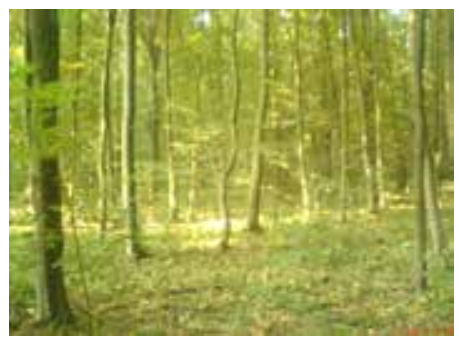

Figure 2.1. Panorama of the site of the soil section № 1 stelleria, violet). The soil is a typical low humus heavy-clay chernozem on D horizon (Figure 2.2).

Description of soil profile:

$\mathrm{H}_{\mathrm{f}}$ 3-0 - forest floor, leaves, buds, tree branches (half decomposed);

H 0-50 - humus, dark gray, dry, heavyclay, slightly compacted, fine-grained, lumpy, intensely penetrated by the roots of grasses and trees, the transition is gradual; 
$\mathrm{Hp}_{\mathrm{k}}$ 51-80 - heterogeneous in colour, the upper part is dark gray with brown colour, the lower part is brown with dark gray hue; compacted, heavyclay, bumpy and slightly blocky, full with roots and occasionally with mole passages. The transition is gradual;

$\mathrm{PH}_{\mathrm{k}}$ 81-140 - dirty-brown, at the top with gray hue, dry, dense, heavy-clay, lumpy and slightly blocky; from the depth of $100 \mathrm{~cm}$ there is weak carbonate mould; slightly penetrated by roots, occasionally with mole passages. The transition is gradual. Soil effervescence is from $10 \%$ of $\mathrm{HCl}$ from the depth of $100 \mathrm{~cm}$.

$\mathrm{P}_{\mathrm{k}}$ 141-170 and deeper is heavy-clay carbonate D horizon.

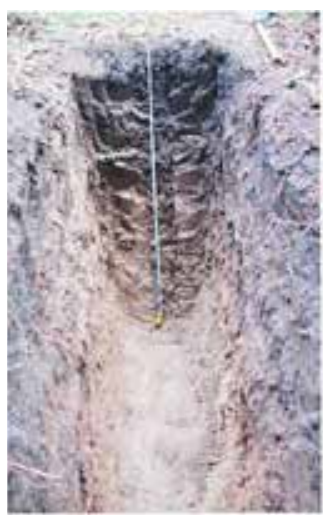

Figure 2.2. Semistationary soil section № 1

Semi-stationary soil section № 2

Soil section № 2 is located $300 \mathrm{~m}$ south of section № 1 . The field under arable land, littered with rape plants (Figure 2.3).

Description of soil profile:

$\mathrm{Ha}_{\mathrm{k}} \mathrm{O}-25 \mathrm{~cm}$ is arable layer, dark gray, dry, heavy-clay, lumpy powder-like soil, (partially cloddy), dense, partially blocky

$\mathrm{H}_{\mathrm{k}} 26-40 \mathrm{~cm}$ is base layer, with much humus, dark gray, over-consolidated, wet, lumpy and blocky, light-clay, the transition is noticeable in structure and density (Figure 2.4).

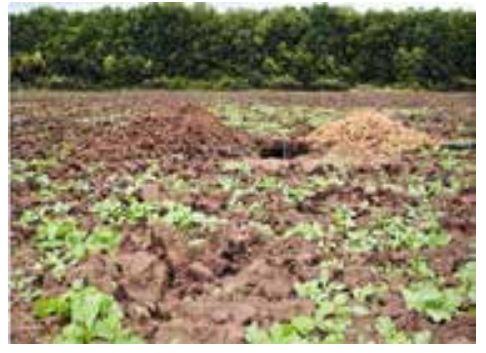

Figure 2.3. Panorama of the location of the ground section № 2

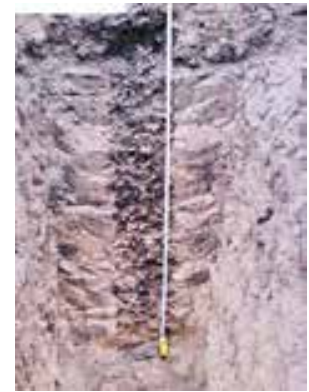

Figure 2.4. Semi-stationary soil section № 2 
$\mathrm{Hp}_{\mathrm{k}}$ 41-50 is dark gray, dry, heavy-clay, very dense, largely blocky; the transition is noticeable by colour;

$\mathrm{PH}_{\mathrm{k}}$ 51-95 is dark gray with a brownish hint, wet, heavy-clay, lumpy, slightly blocky, dense; occasional mole passages and wormholes, the transition is noticeable by consistency;

$\mathrm{Ph}_{\mathrm{k}}$ 96-145 is heterogeneous in colour due to its considerable loosening, dirty-brown with gray tint, wet, heavy-clay, lumpy, slightly blocky, very dense; the transition is noticeable in colour. Soil effervescence is from $10 \%$ of $\mathrm{HCl}$ from the depth of $95 \mathrm{~cm}$;

$\mathrm{P}_{\mathrm{k}}$ 146-170 and deeper is heavy-clay $\mathrm{D}$ horizon with mole passages.

In the chernozem zone, forest only after a long influence slightly increases the content of humus in the soil, slightly reduces soil effervescence, changes the reaction towards acidity and improves the structure. Indeed, we can observe a slightly lower carbonation depth in the forest than in the field. As can be seen from the descriptions of soil profiles in anthropogenically-modified soils, the organic-accumulative horizon is completely absent, and the humus layer, due to the use of machining, is much shorter than that of the natural analogue. Also for this reason, the transitional arable land horizons are consolidated, with a clear transition from one horizon to another.

Modular section 2 (Mala Vyska).

Semi-stationary soil section № 3 .

Let us dwell more on soil sections which are most characteristic of this modular lot.

Section № 3, is located in Dokuchaevka forest belt № 4, $350 \mathrm{~m}$ from Kropyvnytskyi-Uman motorway. It is a flat area. The absolute height is $217 \mathrm{~m}$. The first layer consists of oak, ash and birch bark. The age of the trees is 117 years (Figure 2.5). In the underwood there are black elderberry, Siberian pea shrub; the grass cover is represented by nettle, cow parsley, corydalis, sea flowers and bedstraw. The soil is typical deep humus chernozem in D horizon.

The following genetic horizons are identified:

$\mathrm{H}_{\mathrm{f}}-5-0 \mathrm{~cm}$ is forest floor, half decomposed below.

$\mathrm{H}-0-85 \mathrm{~cm}$ is (where the top layer of $0-10 \mathrm{~cm}$ is characterised with virtually no structural macro- and microaggregates, and is represented by the dusty fraction, probably resulting from the deposition of dust from neigh- 


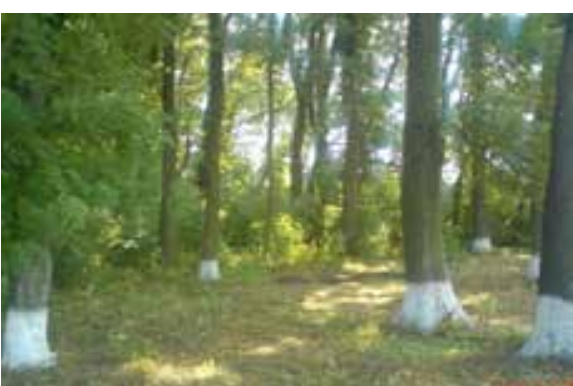

Figure 2.5. Panorama of the location Figure 2.6. Semi-stationary of soil section № 3

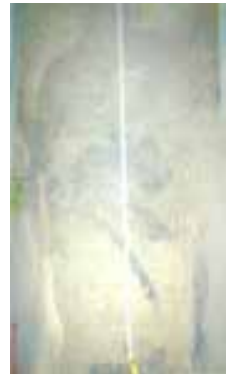

soil section № 3

bouring arable land over the last 100 years. That is the elapsed period after compaction of tree seedlings), porous, humus, dark gray, wet, grainy, lightclay, penetrated with tree roots and mole passages, many coprolites. The transition is gradual (see Figure 2.6).

$\mathrm{Hp}_{\mathrm{k}}-86-105 \mathrm{~cm}$ is upper transitional, humus, dark gray with a brownish hue, wet, granular-bumpy, light-clay, penetrated with mole passages. The transition is gradual.

$\mathrm{PH}_{\mathrm{k}}-106-140 \mathrm{~cm}$ is lower transitional, weak and uneven humus, carbonate, brownish-gray, wet, granular-bumpy, slightly clayey, penetrated with mole passages, large accumulation of carbonates in the wormholes, gradual transition, the soil effervescence is from $10 \%$ of $\mathrm{HCl}$ from the depth of $110 \mathrm{~cm}$.

$\mathrm{P}_{\mathrm{k}}-141-155 \mathrm{~cm}$ and deeper is D horizon of straw colour, carbonate, light-clay, penetrated with mole passages.

Semi-stationary soil section № 4

In the study of soil transformation due to anthropogenic influence, special attention was paid to the study of the genetic structure of the profile and morphological characteristics of soils. As a result of anthropogenic changes that typical and ordinary chernozems have undergone, which first of all includes ploughing with simultaneous change of hydrothermal conditions and subsequent application of fertilizers, ameliorants, cultivation, harrowing and other mechanical treatments, alienation of a large part of the phytomass with crop yield new living conditions are created, unlike natural soil (Figure 2.7). 


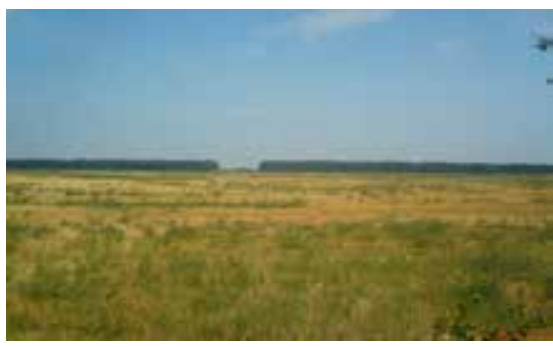

Figure 2.7. Panorama of the location of the ground section № 4
$30 \mathrm{~m}$ away to the north of the forest belt on a flat field, the soil is similar except for the humus horizon, which is shorter by $40 \mathrm{~cm}$ due to partial deflation from the field and settling of dust in the forest belt and considerable compaction of the soil of arable land.

Section № 4. The soil is deep typical chernozem with medium humic in D horizon. The following genetic horizons are identified:

$\mathrm{H}_{\mathrm{a}}-0-18 \mathrm{~cm}$ is arable humus layer, dark gray, wet, dusty-lumpy, lightclay, penetrated with winter wheat roots, compacted;

$\mathrm{H}-19-45 \mathrm{~cm}$ is base layer, well-humic, dark gray, compacted, wet, lumpy and blocky, slightly clayey. The transition is noticeable by consistency.

$\mathrm{Hp}_{\mathrm{k}}-46-85 \mathrm{~cm}$ is upper transitional, humus, very dense, carbonate (soil effervescence of $\mathrm{HCl}$ from the depth of $80 \mathrm{~cm}$; mould carbonates from $80 \mathrm{~cm}$ and to the bottom of the section); dark gray with a brownish hue, wet, coarse-blocky, light-clay, penetrated with mole passages, carbonate-accumulated wormholes, the transition is noticeable by consistency.

$\mathrm{PH}_{\mathrm{k}}-86-140 \mathrm{~cm}$ is lower transitional, slightly and unevenly humic, carbonate, brownish-gray, wet, compacted, coarse-blocky, light-clay, almost not penetrated with mole passages, some carbonates are observed in wormholes.

$\mathrm{P}_{\mathrm{k}}-141-155 \mathrm{~cm}$ and deeper is of straw colour, carbonate, compacted, light-clay, penetrated with mole passages.

Modular section 3 (Kropyvnytskyi).

Semi-stationary soil section № 5 in the village of Sozonivka, Institute of Steppe Agriculture of the National Agrarian Academy of Sciences of Ukraine, is located in the transitional lane of the Buh-Dnipro physical and geographical region of the right bank of the northern Steppe and the southern forest-Steppe. Soil section \# 5 is located on a semi-stationary research site which is on the crossing part on the plain terrain at the distance of $600 \mathrm{~m}$ from the Kropyvnytskyi-Znamyanka motorway in the north direction. Plant cover is represented by grasses. The surface type is a flat plain (Figure 2.8). 


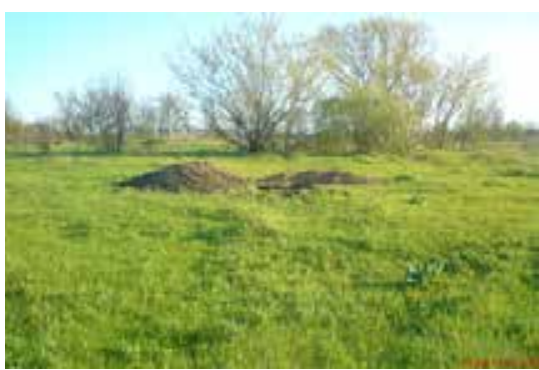

Figure 2.8. Panorama of the location of soil section № 5

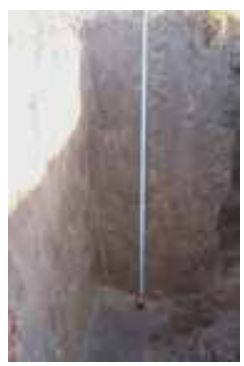

Figure 2.9. Semi-stationary soil section № 5

The soil is ordinary deep chernozem, medium humic, carbonate and light- clay:

$\mathrm{H}_{\mathrm{d}}-(5-0)$ dogwood, consisting of half of the living and dead roots of grass vegetation;

$\mathrm{H}_{\mathrm{k}}$ is a humus horizon, uniformly humic, with a thickness of $55 \mathrm{~cm}$, dark gray with a greyish hue, practically not compacted, wet, has a well-defined granular structure, heavy-clay. Coprolites are widespread throughout the horizon. The transition is gradual (see Figure 2.9); soil effervescence is $10 \%$ of $\mathrm{HCl}$ starts from the surface of the humus horizon;

$\mathrm{HP}_{\mathrm{k}}$ is the upper humus-transition horizon $(56-85 \mathrm{~cm})$. It has gray colour with straw tint. In the upper part of this horizon, the structure is bumpy-granular, porous, which in the lower part turns into a granular-

bumpy with carbonate inclusions in the form of a white star, both in structural features and in root passages. The transition is gradual;

$\mathrm{Ph}_{\mathrm{k}}-86-120 \mathrm{~cm}$, is the lower humus-transition horizon with a greyish-straw colour and many humus stubbles, porous in structural areas and in root passages, clearly visible carbonate inclusions, which in the dry form give it a slight whitishness. In the lower part of the horizon there are carbonates in the form of white stars. The lower transitional boundary extends at the depth of $95-120 \mathrm{~cm}$;

$\mathrm{P}_{\mathrm{k}}-121-150$ and deeper is a straw coloured D horizon, clumped with many mole passages. The upper part is brown, slightly and unevenly humic. Carbonates are present in the form of solid carbonate inclusions, which are rare. The grain-size distribution is light clay. 


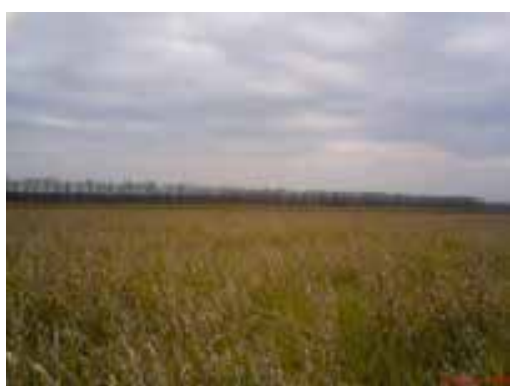

Figure 2.10. Panorama of the location of soil section № 5

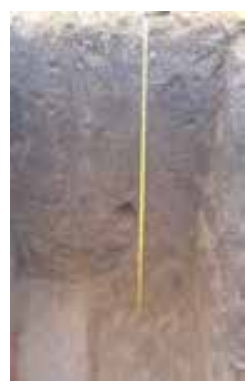

Figure 2.11. Semi-stationary soil section № 6

Semi-stationary soil section № 6

Soil section № 6 is located in field No. 1 of forage crop rotation of the Institute of Steppe Agriculture of the National Agrarian Academy of Sciences of Ukraine in the village of Sozonivka. It is a plain area at the distance of $500 \mathrm{~m}$ from Kropyvnytskyi-Znamyanka motorway. The vegetation is represented by grass mixtures. The surface type is planar (see Figure 2.10).

The soil is ordinary deep medium humic light-clay carbonate chernozem:

$\mathrm{Ha}_{\mathrm{k}}-0-20 \mathrm{~cm}$ is arable layer of humus horizon, uniformly humic (soil effervescence of $\mathrm{HCl}$ from the depth of $10 \mathrm{~cm}$ ) dark gray colour with a greyish tint, compacted, wet, dusty-lumpy (see Figure 2.11);

$\mathrm{H}_{\mathrm{k}}-21-43 \mathrm{~cm}$ is base layer of humus horizon, uniformly humic, very compacted, especially at the depth of 30-40 cm, dark gray with greyish tint, lumpy and blocky, some mole passages are found all over the layer. The transition is noticeable by consistency;

$\mathrm{HP}_{\mathrm{k}}-44-69 \mathrm{~cm}$ is the first humus-transition horizon, gray with straw colour tint, very dense. At the top of this horizon the structure is lumpy and blocky, which in the lower part turns into blocky and lumpy,

and at the bottom with carbonate inclusions which are present both in structural features and in root passages. The transition is clearly visible;

$\mathrm{Ph}_{\mathrm{k}}-70-100 \mathrm{~cm}$ is the second humus-transition horizon, compacted, has straw-gray colour and much humus. In the dry state the horizon breaks down into lumps of different sizes and considerable hardness. The lower transitional boundary extends to the depth of $100 \mathrm{~cm}$; 
$P_{k}-101-150$ and deeper, there is straw colour carbonate D horizon, lumpy with many mole passages. The upper part is dark brown, slightly and unevenly humic. The grain-size distribution is light clay.

Semi-stationary soil section № 7

Semi-stationary section № 7 is located in the western outskirts of Kropyvnytskyi in the transition zone of the Dnipro upland, on the border of the forest-steppe crossing to the Steppe. Soil section \# 7 is located on a semi-stationary research site on a turning part on a plain terrain at the distance of $100 \mathrm{~m}$ in the southern direction of Kropyvnytskyi-Mala Vyska. The plant cover is represented by grasses. The surface type is planar (see Figure 2.12).

The soil is typical carbonate chernozem with medium humus and light clay:

$\mathrm{H}_{\mathrm{d}}-(5-0)$ dogwood, consisting of half of the living and dead roots of herbaceous vegetation;

$\mathrm{H}_{\mathrm{k}}$ is uniformly humic, with the capacity of $47-48 \mathrm{~cm}$, (soil effervescence of $\mathrm{HCl}$ from the depth of $5 \mathrm{~cm}$ ) dark gray colour with grayish tint, moderately compacted, dry, has a well-expressed lumpy and blocky structure. Coprolites are widespread throughout the horizon. The transition is gradual;

$\mathrm{Hp}_{\mathrm{k}}$ is upper humus-transition horizon, (49-77 cm). It has gray colour with a straw tint. In the upper part of this horizon, the structure is lumpy, blocky, very compacted at the depth of 50-60 cm, which in the lower part becomes a large-blocky with carbonate inclusions in the form of mould and tubules, which are widespread, both in structural areas and in root passages. The transition is clearly expressed (Figure 2.13);

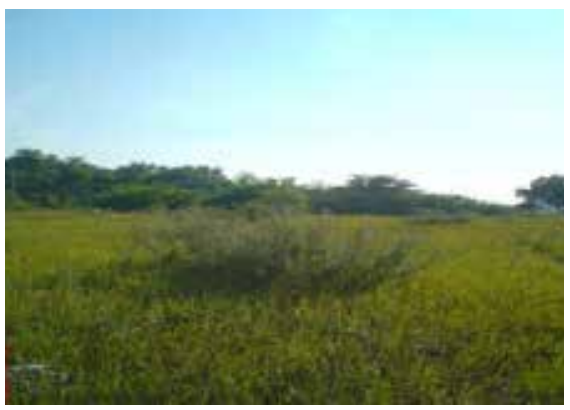

Figure 2.12. Panorama of the location of the ground section № 7

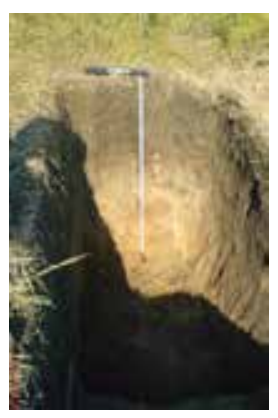

Figure 2.13. Semi-stationary soil section № 7 
$\mathrm{PH}_{\mathrm{k}}$ is lower humus-transitional horizon at $78-95 \mathrm{~cm}$. It has grayish colour, compacted on the structural parts and on the root passages clearly show carbonate inclusions, which in the dry form give it a slight whitishness. The upper part of this horizon is largely blocky. In the lower part of the horizon there are carbonates in the form of mould. The lower transitional boundary extends at the depth of $85-95 \mathrm{~cm}$;

$\mathrm{P}_{\mathrm{k}}-96-150$ and deeper straw-coloured carbonate D horizon, clumped with some mole passages. The upper part is dark brown, slightly and unevenly humic. Carbonates are present in the form of moulds that acquire single interspersion. The grain-size distribution is light clay.

The presence of blocky structure, which is not characteristic of grass lands, especially at the depth of 50-60 cm, can be explained by the fact that this site has not yet managed to restore its structure.

Semi-stationary soil section № 8

The semi-stationary section \# 8 is located in the southeastern outskirts of Kropyvnytskyi in the transition zone of the Dnipro heights, on the border of the forest-steppe crossing to Steppe. Soil section No. 8 is located on a semi-stationary research site of the State Forestry Organization on plain terrain at the distance of $500 \mathrm{~m}$ from Kropyvnytskyi ring road. The vegetation is represented by the family of Solanaceae. The surface type is planar (Figure 2.14). The soil is typical chernozem with medium humus and heavy-clay carbonate:

$\mathrm{Ha}_{\mathrm{k}}-$ 0-19 $\mathrm{cm}$ arable humic layer, dark gray, almost black, wet, lumpy and grainy, heavy-clay, loose;

$\mathrm{H}_{\mathrm{k}}-20-41 \mathrm{~cm}$ is base layer, well-humic, dark gray, loose, lumpy and grained, heavy-clay. The transition is barely noticeable by colouring (Figure 2.15);

$\mathrm{H}_{\mathrm{pk}}$ is upper humus-transition horizon $(42-75 \mathrm{~cm})$. It has a gray colour with a straw tint. In the upper part of this horizon, the structure is lumpy-granular, porous, which in the lower part turns into granular-lumpy with carbonate inclusions in the form of moulds and tubes, which are distributed both in structural parts and in root passages.

Soil effervescence is $10 \%$ of $\mathrm{HCl}$ from the depth of $40 \mathrm{~cm}$. The transition is gradual;

$\mathrm{P}_{\mathrm{hk}}-76-110 \mathrm{~cm}$ is the lower humus-transition horizon, has grayish colour and many swaths of humus, porous in structural areas and in the root 


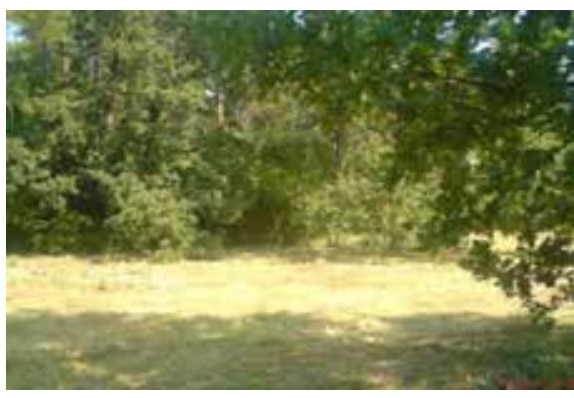

Figure 2.14. Panorama of the location of soil section № 8

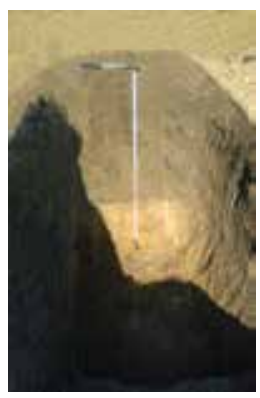

Figure 2.15. Semi-stationary soil section № 8

passages, clearly visible carbonate inclusions, which in the dry form give it a slight whitishness. In the lower part of the horizon there are carbonates in the form of white stars. The lower transitional boundary extends at the depth of $95-110 \mathrm{~cm}$;

$\mathrm{P}_{\mathrm{k}}-111-170 \mathrm{~cm}$ and deeper is straw-coloured carbonate D horizon, clumped with many mole passages. The upper part is dark brown, slightly and unevenly humic. Carbonates are present in the form of moulds, which acquire a single interspersion, and from the depth of $170 \mathrm{~cm}$ solid carbonate inclusions rarely appear. The grain-size distribution is heavy clay.

As can be seen from the descriptions of soil sections, the humus horizon of natural soils is uniformly coloured in dark gray to the depth of $49-55 \mathrm{~cm}$. This is due to the fact that soil tillage is applied and heavy machinery compacts it, thus degrading the agro-environmental properties. But the arable land, which has been cultivated for a long time in a non-mechanized way, is represented by section No. 8 in the humus horizon and has a distinctly lumpy-grained structure. This structure, together with low density, creates favourable conditions for the development of crops.

Modular section 4 (Oleksandria).

Soil section № 9 of Oleksandria State Variety Research Station

In order to identify the agro-ecological impact on soil condition of Oleksandria State Variety Research Station, a pilot lot was selected, which includes two soil sections: in the territory of the oak planting (see Figure 2.16) and in the territory of the experimental field. The total depth of both sections is $150 \mathrm{~cm}$. 


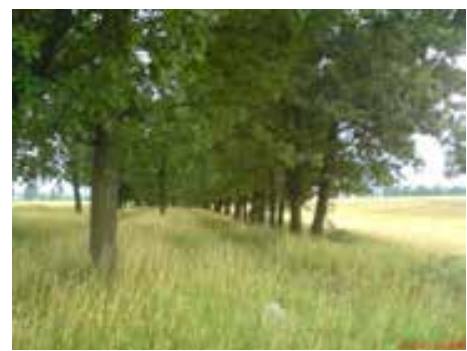

Figure 2.16. Panorama of the location of soil section № 9

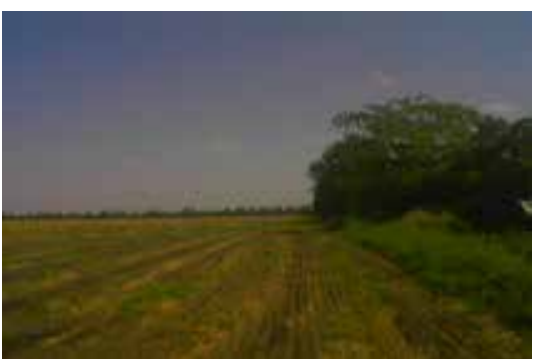

Figure 2.17. Panorama of the location of soil section № 10

Soil section No. 9 is located outside the economic activity of people. The soil is ordinary deep chernozem with medium humus, heavy-clay, which is divided into the following horizons:

$\mathrm{H}_{\mathrm{o}}-$ (3-0) forest floor, leaves, buds, tree branches (semi-decomposed);

$\mathrm{H}-(0-60 \mathrm{~cm})$ is humus, porous, dark gray, wet, heavy-clay, granular structure, the upper layer $(0-15 \mathrm{~cm})$ was formed due to deflation processes and is characterized by almost complete absence of macrostructure;

$\mathrm{HP}_{\mathrm{k}}$ is upper transitional $(61-90 \mathrm{~cm})$, moderately compacted, dark gray, with a brownish-bluish tint, closer to the lower boundary gradually lightens, heavy-clay mechanical composition, the upper boundary of the horizon is granular, the lower structure turns into thickened, slimy with many plant roots, soil effervescence is from the depth of $75 \mathrm{~cm}$, carbonates are found everywhere in the form of white stars. The transition is gradual;

$\mathrm{Ph}_{\mathrm{k}}$ is lower transitional $(91-115 \mathrm{~cm})$, carbonate, dark brown, wet, heavy-clay, lumpy-granular-blocky-like, compacted, strongly penetrated with mole passages, there are many carbonate inclusions along the roots;

$\mathrm{P}_{\mathrm{k}}-116-150$ and deeper is D horizon, brown tint, spotted, heavy-clay granulometric composition, compacted.

Semi-stationary soil section No. 10

The land forms of Oleksandria experimental site, on which the soil section No. 10 is located, is a plateau (see Figure 2.17), with a general slope of the horizon in the southeast. In the north-east and south-western parts of the territory are cutbanks with general slope of $2^{\circ}$. Outside Oleksandria State Variety Research. 
Station the cutbanks turn into denes of heavy-clay, dusty-granular structure. Winter wheat stubble. The experiment was carried out immediately after the harvest. The soil is ordinary deep chernozem with low humus and heavy clay. Total depth of field section is $150 \mathrm{~cm}$, which is divided into the following horizons:

$\mathrm{H}_{\mathrm{a}}$ is arable $(0-25 \mathrm{~cm})$, with humus, compacted, dark gray, wet;

$\mathrm{H}$ is under-tilling $(26-35 \mathrm{~cm})$, with humus, compacted, dark gray colour, heavy-clay, blocky-like structure, plant roots are present. The transition is noticeable by consistency;

$\mathrm{HP}_{\mathrm{k}}$ is upper transitional (36-70 cm), very compacted, dark gray, sometimes almost black with a brownish-bluish tint, closer to the lower boundary gradually lightens, heavy-clay mechanical composition, the upper boundary of the horizon is coarse-grained, lower thickening with plant roots, carbonates are found from the depth of $55 \mathrm{~cm}$, soil effervescence is $10 \%$ of $\mathrm{HCl}$. The transition is noticeable by consistency;

$\mathrm{Ph}_{\mathrm{k}}$ is lower transitional (71-90 cm), compacted, greyish-green colour, at the lower part of the horizon lightens, gradually gaining the colours of soil-forming rock, fine-grained, heavy-clay, carbonated, perennial; the transition is noticeable by consistency.

$\mathrm{P}_{\mathrm{k}}-91-150 \mathrm{~cm}$ and deeper is D horizon of straw colour, dense, light clay with granulometric composition.

Ordinary chernozem approaching deep chernozem by its features. Our research shows the reverse process, although the carbonation effervescence for forest belts is actually lower than for the arable land.

Modular section 5 (Novoukrainka).

Semi-stationary section № 11 is the grass land aged 10 years in the northern suburbs of the town of Novoukrainka, LLC "Zernovyk". It is located in the steppe part of the Dnipro upland, the subzone of the northen Steppe. It is the plain at the distance of $3 \mathrm{~km}$ from the town. The surface type is planar. In the eastern direction of $100-150 \mathrm{~m}$ are small embankments formed artificially during the construction of the railway (Figure 2.18).

The soil is ordinary chernozem with low humus and light clay:

$\mathrm{H}_{\mathrm{d}}$ - (5-0) steppe mat, remnants of herbaceous vegetation;

$\mathrm{H}_{\mathrm{k}}$ is humus horizon, uniformly humic, $50 \mathrm{~cm}$ thick, dark gray with a brownish tint, heavy-clay, porous, dry, lumpy-granular, considerably pen- 


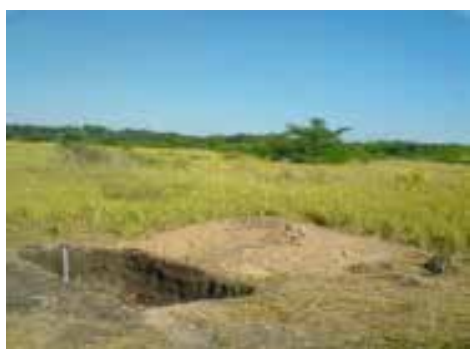

Figure 2.18. Panorama of the location of soil section № 11

\section{Figure 2.19. Semi-stationary soil section № 11}

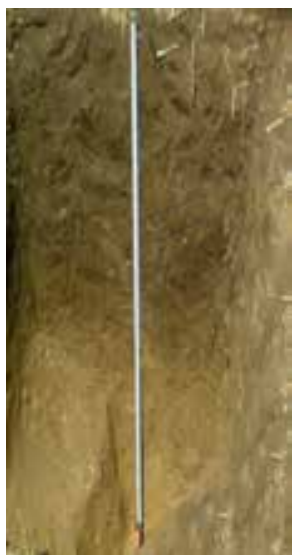

etrated by worms and insects, some mole passages and roots of plants that are traced by carbonate inclusions. Effervescence is $10 \%$ of $\mathrm{HCl}$ from the depth of $20 \mathrm{~cm}$. The transition is gradual;

$\mathrm{HP}_{\mathrm{k}}$ is upper transitional horizon, $30 \mathrm{~cm}$ thick, dark gray with a brownish tint, wet, light clay, lumpy-granular, slightly compacted, at the bottom with carbonate inclusions, which is widespread both in structural features and in roots. The transition is gradual (see Figure 2.19);

$\mathrm{Ph}_{\mathrm{k}}$ is $(81-110 \mathrm{~cm})$ lower transitional horizon, dark brown, wet, light clay, lumpy, compacted, penetrated with mole passages. In the lower part of the horizon there are carbonates in the form of fibers. The lower transitional boundary is located at the depth of $110 \mathrm{~cm}$, the transition is gradual;

$\mathrm{P}_{\mathrm{k}}-111 \mathrm{~cm}$ and deeper is $\mathrm{D}$ horizon of straw colour, at the upper part weakly and unevenly humic, compacted, depths of 90-140 cm. The grainsize distribution is light clay.

Semi-stationary soil section № 12

Soil section № 12 is located on the above-mentioned experimental lot. It is a plain terrain at the distance of $150 \mathrm{~m}$ from section \# 10 in the northeast direction in field № 1 of LLC "Zernovyk". The field is sown with winter barley. The type of surface is planar (see Figure 2.20)

The soil is ordinary chernozem with low humus and light clay:

$\mathrm{H}_{\mathrm{a}}-0-20 \mathrm{~cm}$ of arable horizon, uniformly humic, dark gray with brownish tint, moderately compacted, dry, lumpy and blocky; 


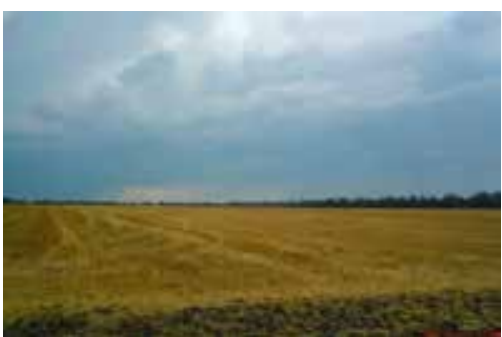

Figure 2.20. Panorama of the location of soil section № 12

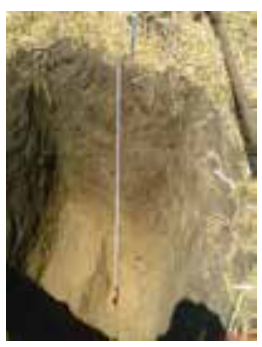

Figure 2.21. Semi-stationary soil section № 12

$\mathrm{H}-21-38 \mathrm{~cm}$ is base layer, uniformly humic, dark gray with a brownish tint, compacted, blocky, mole passages occur throughout the layer. The transition is noticeable by consistency;

$\mathrm{HP}_{\mathrm{k}}-39-63 \mathrm{~cm}$ is upper transitional horizon, dark gray with more saturated brownish tint (Fig. 2.21), lumpy and blocky, very compacted, at the bottom with carbonate inclusions, which are widespread both in structural features and in root passages. Soil effervescence is $10 \%$ of $\mathrm{HCl}$ from the depth of $40-45 \mathrm{~cm}$. The transition is noticeable by consistency;

$\mathrm{Ph}_{\mathrm{k}}-64-109 \mathrm{~cm}$ is lower transitional horizon, dark brown, very compacted, carbonate passages are full of visible carbonate inclusions, which in the dry form give it a slight whiteness. At the bottom of the horizon there are solid carbonate inclusions. The lower transitional boundary extends at the depth of 85-109 cm;

$\mathrm{P}_{\mathrm{k}}-110$ and deeper is $\mathrm{D}$ horizon, compacted, with many mole passages. The upper part is light brown, slightly and unevenly humic. Carbonates are present in the form of a white star. The mechanical composition is light clay.

As can be seen from the descriptions of soil profiles in anthropogenically-altered soils, the organic-accumulative horizon is completely absent, and the humus, due to the use of machining, is much shorter than that of the natural counterpart, even if the adjacent horizon is arable, they clearly show the transition from one to another.

Modular section 6 (Dolynska).

Semi-stationary soil section № 13

In the territory of Dolynska district, which is steppe zone, the most widespread are ordinary low-humus shallow chernozems. There are 


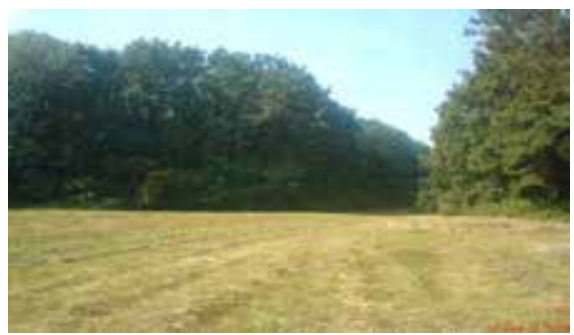

Figure 2.22. Panorama of the location of soil section № 13

Figure 2.23. Semi-stationary soil section № 13

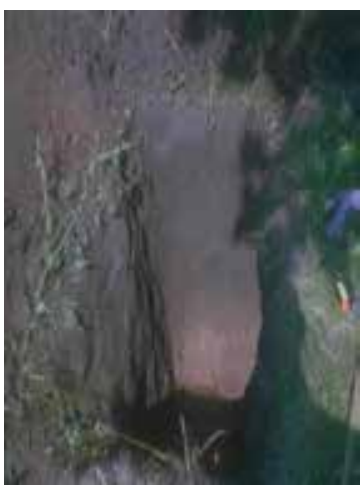

also ordinary, medium illuvial chernozems; ordinary low-humus chernozems, and ordinary low- and medium-humus, deep chernozems (Figure 2.22). The landscape of the experimental lot of the landscape park is a plateau surrounded by mixed forest with the slope of the horizon in the eastern direction. The soil is ordinary medium humus, light-clay chernozem.

he total depth of the soil section is $150 \mathrm{~cm}$, which is divided into the following horizons (see Figure 2.23):

$\mathrm{H}_{\mathrm{d}}-(5-0)$ is steppe mat, remnants of herbaceous vegetation (half decomposed);

$\mathrm{H}-0-60 \mathrm{~cm}$ is light clay, lumpy-grainy, intensely dark gray, wet, porous, significantly penetrated with the roots of herbs and trees. The transition to the next horizon is gradual;

HP is upper transitional (61-85 cm), well humic, light clay, poorly compacted, gray, wet,

granular-lumpy, from the depth of $60 \mathrm{~cm}$ weak carbonate inclusions appear, as evidenced by a moderate soil effervescence of $10 \% \mathrm{HCl}$, the transition gradual;

$\mathrm{Ph}_{\mathrm{k}}$ is lower transitional ( $\left.86-125 \mathrm{~cm}\right)$, gray with a brown tint, wet, light clay, blocky, compacted. The transition is gradual;

$P_{k}$ is 126-150 and deeper light-clay, yellowish, wet, largely blocky, carbonate inclusions in the form of lumps $0.5-1.5 \mathrm{~cm}$ in size; 
Semi-stationary soil section № 14

In order to determine the agro-ecological impact on the soil condition as a result of agricultural use, an experimental lot was selected in the territory of the third field of the production rotation in Bokovenky Landscape Parknamed named after Davydov. One soil section was made on it. The soil is ordinary, medium humus, light-clay chernozem. The total depth of the soil section is $150 \mathrm{~cm}$, which is divided into the following horizons:

$\mathrm{H}_{\mathrm{k}}$ is tillage pan $(26-40 \mathrm{~cm})$, humic,

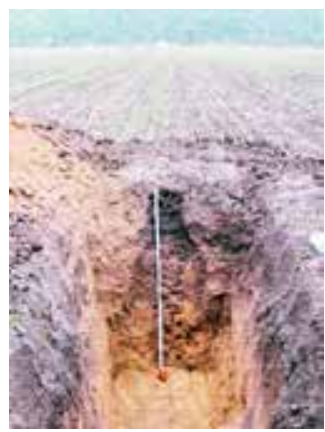

Figure 2.24. Semi-stationary soil section № 14 very compacted, dark gray, wet, heavy-clay, blocky with traces of plant roots. The transition is noticeable by consistency, soil effervescence is $10 \%$ of $\mathrm{HCl}$ from the depth of $35 \mathrm{~cm}$ (Figure 2.24);

$\mathrm{HP}_{\mathrm{k}}$ is upper transitional $(41-70 \mathrm{~cm})$, lumpy-blocky structure, compacted, dark gray with slight brownish tint in the lower part gradually luminous, light-clay, the structure of the upper part is coarse-blocky, in the lower part turns into coarse-lumpy and compacted. At depths of $45-50 \mathrm{~cm}$ there are carbonate inclusions in the form of moulds;

$\mathrm{Ph}_{\mathrm{k}}$ is lower transitional $(71-95 \mathrm{~cm})$, carbonate, dark brown, light-clay, lumpy-granular-blocky, slightly compacted. In the traces of the roots there are many carbonate inclusions. The transition is noticeable by consistency;

$\mathrm{P}_{\mathrm{k}}$ is 96-150 and deeper $\mathrm{D}$ horizon, the upper part is light-brown, slightly below the yellow colour, light-clay grain-size distribution with carbonate inclusions.

\section{Anthropogenic changes in soil structure}

Soil structure is its property to form aggregates of certain shape and size and to decay under the influence of little effort into the elements. The elements are called structural. Structural elements can be different in size, shape and hardness. The size of the lumps is distinguished as follows: soil microstructure - the aggregates with the diameter up to $0.25 \mathrm{~mm}$, soil macrostructure (lumpy-granular) - 0.25-10 $\mathrm{mm}$ and soil mega-structure - more than $10 \mathrm{~mm}$. By the form of aggregates, the structure can be lumpy, blocky, granular, dusty, columnar, prismatic and plastic. 
The agronomic value of the structure depends on the roughness of the aggregates, which in turn is related to the density of the micro-aggregates in the macro-aggregates. The considerable lumpiness of lumps together with moisture resistance determines positive physical properties of soils. It is an indicator of the structure and high degree of cultivation of the soil (Table 1).

Table 1

Changes in soil structure depending on the type of land use

\begin{tabular}{|c|c|c|c|c|}
\hline \multirow{2}{*}{$\begin{array}{c}\text { Agro-eco } \\
\text { system type }\end{array}$} & \multicolumn{4}{|c|}{ Type of structure by depths, cm } \\
\hline & $0-20$ & $30-50$ & $60-90$ & $90-120$ \\
\hline \multicolumn{5}{|c|}{\begin{tabular}{|l|} 
Forest-steppe zone \\
\end{tabular}} \\
\hline Forest & $\begin{array}{l}\text { small-granular } \\
\text { - lumpy }\end{array}$ & $\begin{array}{l}\text { small-granular } \\
\text { - lumpy }\end{array}$ & $\begin{array}{l}\text { lumpy-light } \\
\text { blocky }\end{array}$ & $\begin{array}{l}\text { lumpy-light } \\
\text { blocky }\end{array}$ \\
\hline Forest belt & granular & granular & granular-lumpy & $\begin{array}{l}\text { lumpy-light } \\
\text { blocky }\end{array}$ \\
\hline Arable land & cloddy & lumpy-blocky & $\begin{array}{l}\text { lumpy-light } \\
\text { blocky }\end{array}$ & $\begin{array}{l}\text { lumpy-light } \\
\text { blocky }\end{array}$ \\
\hline \multicolumn{5}{|l|}{ Transitional line } \\
\hline Forest belt & granular & granular & granular-lumpy & $\begin{array}{l}\text { lumpy- } \\
\text { granular-blocky }\end{array}$ \\
\hline Grass land & granular & granular & lumpy-granular & lumpy-granular \\
\hline $\begin{array}{l}\text { Arable land } \\
\text { (machine } \\
\text { cultivation) }\end{array}$ & dusty-lumpy & lumpy-blocky & lumpy-blocky & lumpy \\
\hline $\begin{array}{l}\text { Arable land } \\
\text { (non-machine } \\
\text { cultivation) }\end{array}$ & $\begin{array}{l}\text { clumpy- } \\
\text { granular }\end{array}$ & lumpy-granular & lumpy-granular & lumpy-granular \\
\hline \multicolumn{5}{|l|}{ Steppe zone } \\
\hline Forest & lumpy-granular & lumpy-granular & \begin{tabular}{|l|} 
granular-lumpy \\
\end{tabular} & blocky \\
\hline Grass land & lumpy-granular & lumpy-granular & lumpy & lumpy \\
\hline Arable land & light-cloddy & blocky & lumpy-blocky & $\begin{array}{l}\text { lumpy- } \\
\text { granular-blocky }\end{array}$ \\
\hline
\end{tabular}

Structural aggregates may be unevenly located in the bulk of the soil. The porosity of the soil and its bulk depends on it. The ratio of soil solids to pore volume, as well as capillary and non-capillary porosity, depends to a large extent on the soil structure and the methods and intensity of its cultivation. No less important feature of soil is its structure, that is, the ability 
to break up into separate elements [1, p. 99]. Structure is one of the most important properties of soils, which significantly affects fertility. Considering structure as a morphological feature, it is first of all necessary to pay attention to the shape, size and qualitative state of aggregates in different types of soils, as well as different genetic horizons of the same soil, where they are different.

The agro-ecological importance of soil structure is that it directly affects physical, water, physical-mechanical properties and resistance of soil to erosion phenomena.

The soil structure, which is dominated by aggregates of lumpy-granular structure with the size from 10 to $0.25 \mathrm{~mm}$, has a loose soil composition, lower density and greater porosity. The unstructured soil has only capillary slots, and the structural soil has capillary and large pores, both between the aggregates and inside them, which are filled with air (see Table 3.1). Soils of natural ecosystems in all study areas have a distinct lumpy-granular and granular structures, and therefore they evaporate (and lose) moisture, unlike agro-ecosystems where mechanized tillage is used, which is a non-structural soil. As can be seen from the table, the soils of agro-ecosystems where mechanized tillage of the soil in the layer are used have a dusty-lumpy structure. This indicates that they are gradually turning into unstructured soils. Down the profile of their structure changes dramatically and takes the form of natural analogues.

The depth of difference between natural and agro-ecosystems coincides with the depth of difference in soil density. Agro-ecosystems without mechanization have a lumpy-granular structure and hold an intermediate position between natural and agro-ecosystems. The structure has a great influence on the permeability to the air. In the unstructured soil of agro-ecosystems with mechanized tillage and with sufficient moisture content of the plant roots and aerobic microflora suffer from the lack of free oxygen. And with sufficient air content, on the contrary, they suffer from the lack of moisture. That is why the relationship between solid and liquid and gaseous phases of soils is optimal in structural soils of natural ecosystems.

Moisture is slowly absorbed by soil of agro-ecosystems. In spring, during melting of snow and heavy rainfalls (especially they are characteristic of the steppe zone), a large amount of water on the slopes flows down to the surface of the soil, is lost and causes erosion, and the plaques show 
water stagnation and flooding of the topsoil. In such conditions, soils that are formed, have a cloddy structure. The predominance of this structure significantly impairs, and sometimes makes impossible the processes of moisture and air exchange between soil and plant, and as a consequence leads to their degradation.

There is no antagonism between water and air in the soil cover of grass land and forest ecosystems. With sufficient moisture available to plants, the structural soil contains the optimum amount of air.

At the same time, soils of grass land and agro-ecosystems without mechanized tillage are more resistant to water and wind erosion. Loose (structural) soil composition promotes better seed germination, propagation of plant roots in the soil. The dusty-lumpy structure of soils of agro-ecosystems after wetting floats, when it dries, forms a crust, which impedes the germination of seeds. The range of optimal soil moisture for cultivation is broader in the soil of the steppe eco-systems compared to the dusty-lumpy and cloddy agro-ecosystems throughout the study areas.

Therefore, these features just cause higher soil fertility of natural ecosystems compared to agro-ecosystems. No less important argument in favour of soils of agro-ecosystems where mechanized cultivation was not applied is that its cultivation consumes less energy costs [2, p. 292; 3, p. 170].

\section{Conclusions}

A significant improvement of the ecological status will result in the introduction of soil protection system of soil tillage, which will impede the development of water and wind erosion processes, significantly reduce the cost of labour, fuel and lubricants during this activity.

Paying attention to the comprehensive biologicalisation of agriculture, enriching its environmental functions can increase the efficiency of agricultural production, ensure high quality indicators of production and entering the world market. According to S.H. Chornyi, in modern agriculture, the role of the concept of "soil quality" is increasing, especially its definition, which consists not only of production functions, but also of ecological and social components. They are the main means of agricultural production, an indispensable material condition of human life and society, an inexhaustible source of its national wealth and prosperity [4, p. 7]. 
For the rational and highly efficient use of land and restoration of soil fertility it is necessary not only to know deeply and comprehensively the origin, composition and properties of soils, but also to have an objective and reliable assessment of their quality as a natural and historical basis for the development and implementation of soil protection systems of agriculture aimed at reproduction of soil fertility [5, p. 14].

\section{References:}

1. Topolnyi F.P., Mostipan M.I., Gelevera O.F., Vakhnyak V.S. (2014). Gruntoznavstvo z osnovamy geologii ta geographii gruntiv: Textbook [Soil science with the basics of geology and soil geography]. Kirovohrad: Publisher L.F. Lysenko. (in Ukrainian)

2. Bulyhin S.Yu., Tonkha O.L., Vitvitskyi S.V., Pikovska O.V., Antonyuk D.O. (2018). Reglamentuvannya technichnogo navantagennya na grunty [Regulation of technological load on soils] Agrochemistry and soil science. Interagency thematic scientific collection of works. Special issue. Book 2. Melioration, reclamation, soil protection, agro-chemistry, humus condition, soil biology, organic farming. Kharkiv: PE "Style-Issue", pp. 290-296. (in Ukrainian)

3. Medvedev V.V. (2012). Monitoryng pochv Ukrainy. Koncepciya. Itogy. Zadachy: monohrafiia. [Soil monitoring of Ukraine. Concept. Outcomes. Tasks $\left(2^{\text {nd }}\right.$ revised and supplemented edition)]. Kharkov: KP "City Printing House". (in Ukrainian)

4. Chornyi S.H. (2018). Ocinka yakosti gruntiv: monohrafiia. [Soil quality assessment: textbook]. Mykolaiv: MNAU. (in Ukrainian)

5. Kovalov M.M. (2011). Agrofizychna degradaciia gruntiv - problema syohodeniia [Agrophysical degradation of soils - the problem of the present]. Materialy XLII naukovoi konferentsii vykladachiv, aspirantiv ta spivrobitnykiv Kirovohradskoho nacionalnoho technichnoho univerciteta. Kirovohrad. (in Ukrainian) 